\title{
Neural Correlates of Impulsive Buying Tendencies during Perception of Product Packaging
}

\author{
Marco Hubert and Mirja Hubert \\ Zeppelin University
}

\author{
Arnd Florack \\ University of Vienna
}

\section{Marc Linzmajer}

University of St. Gallen

Peter Kenning

Zeppelin University

\begin{abstract}
Research has shown that people differ in their susceptibility to impulsive buying. The appeal of product packaging has the potential to trigger impulsive buying even for consumers with no intention to make a purchase. The aim of the present study was to investigate whether individual differences in consumers' impulsive buying tendencies affect unconscious neural responses during the perception of product packaging. Functional magnetic resonance imaging (fMRI) was applied to measure neural responses to the perception of product packages in participants with different impulsive buying tendencies. The results of the study support and expand prior research in impulsive and reflective information processing and behavior. First, attractive versus neutral packages evoked more intensive activity changes in brain regions associated with an impulsive system. Second, attractive and unattractive versus neutral packages led to less intensive activity changes in regions associated with a reflective system. Third, attractive packages activated regions associated with reward, whereas unattractive packages activated regions associated with negative emotions. The results suggest that there is indeed a corresponding relationship between stronger impulsive buying tendencies and activity in brain areas associated with impulsive and reflective processes. (C) 2013 Wiley Periodicals, Inc.
\end{abstract}

Shoppers browsing the aisles of a supermarket encounter a wide array of product packages that have been designed to influence the consumer to buy the products-and the attempt to arouse a desire to purchase is often successful (Ambler, Braeutigam, Stins, Rose, \& Swithenby, 2004; Bloch, 1995; Kacen $\&$ Lee, 2002). Consumers are more likely to choose products that have an attractive appeal than they are to select similar but less visually appealing products (Kotler \& Rath, 1984). As well, an appealing product packaging can evoke an impulse to buy even when the consumer had not planned to purchase that product (Rook \& Fisher, 1995; Vohs \& Faber, 2007). However, research has also shown that consumers differ in their susceptibility to follow such impulses (Kacen \& Lee, 2002; Kaufman-Scarborough \& Cohen, 2004; Rook \& Fisher, 1995; Spears, 2006; Verplanken \&
Herabadi, 2001). While there is growing evidence supporting interindividual differences in impulsive buying tendencies, the neural mechanisms underlying these differences are not yet well understood. In the present article, theories of impulsive and reflective determinants of behavior from social psychology (Strack \& Deutsch, 2004; Strack, Werth, \& Deutsch, 2006) and neuroscience (Bechara, 2005) were used to illuminate the neural processes correlated with the perception of attractive product packaging in consumers who vary in impulsive buying ${ }^{1}$ tendencies.

Note that the term "impulse buying" is frequently used as a synonym for impulsive buying. 


\section{THEORY}

Impulsive buying behavior has been regarded as affect-driven, spontaneous behavior that occurs without extensive deliberation about reasons to buy a product (Vohs \& Faber, 2007; Weinberg \& Gottwald, 1982). A widely accepted definition of impulsive buying frames the behavior of an impulsive buyer as "a sudden, often powerful and persistent urge to buy something immediately" that is "prone to occur with diminished regard for its consequences" (Rook, 1987, p. 191). Impulsive buying behavior affects many consumers (Gutierrez, 2004), and often does so with negative consequences (Dittmar \& Drury, 2000; Hausman, 2000; Luo, 2005; Rook, 1987; Rook \& Fisher, 1995). For instance, research indicates that impulsive buying may result in feelings of guilt on the part of the buyer, and social disapproval toward the buyer (Rook, 1987). As well, impulsive buying is understood to be at least partly responsible for consumer debt and bankruptcy filings (Vohs \& Faber, 2007; Wood, 1998).

Research on the phenomenon of impulsive buying is extensive. A significant group of those studies has revealed a number of context variables that either enhance or decrease the likelihood of impulsive buying behavior (Beatty \& Ferrell, 1998; Friese, Wänke, \& Plessner, 2006; Kollat \& Willett, 1967; Luo, 2005; Verplanken \& Herabadi, 2001; Vohs and Faber, 2007). To understand the effects of such context variables, it is necessary to consider the processes that underlie these effects. Drawing on models that were developed to explain general impulsive behavior (e.g., Strack \& Deutsch, 2004; Strack, Werth, \& Deutsch, 2006), it is assumed that context variables can either affect the activation or strength of impulses, or have an influence on the strength of self-control (Shiv \& Fedorikhin, 1999, 2002). For instance, the presence of attractive marketing cues may stimulate the impulse to buy, whereas the presence of family members during shopping may increase self-control and thus reduce impulsive buying (Luo, 2005).

The idea of the emergence of impulsive buying behavior from the interplay between impulsive and reflective processes triggered through context variables is in line with dual process models that attempt to explain general impulsive behavior (Strack \& Deutsch, 2004). The dual process models are based on the assumption that fast automatic impulsive processes compete with slow reflective processes that demand cognitive resources (Strack \& Deutsch, 2004; Strack, Werth, \& Deutsch, 2006). The model developed by Strack and Deutsch (2004) corresponds to theories and empirical studies that are concerned with the neural correlates of impulsive behavior (Bechara, 2005; Dawe, Gullo, \& Loxton, 2004; Gray, 1982; Jentsch \& Taylor, 1999; Lieberman, 2007; Pickering \& Gray, 1999). In a very sophisticated integration of the current knowledge into the field of social neuroscience, Bechara (2005) developed a theory that distinguishes an impulsive brain system from a reflective system.
He proposes that behavioral decisions are based on signals stemming from neural processes within the impulsive and reflective systems. Additionally, he assumes that during decision making, immediate and future prospects trigger conflicting responses in the impulsive and reflective systems of the brain. A central hypothesis of this model is that strong signals are reinforced, whereas weak ones are overridden. At the end of these competing processes, an overall signal emerges that drives the decision (winner takes all). In line with Strack and Deutsch (2004), Bechara (2005) assumes that a hyperactivity-an overactive, highly sensitive process-of the impulsive system (Burns \& Bechara, 2007) can weaken control of the reflective system, and can thus result in impulsive behavior.

Though research has provided results supporting the basic assumptions of neurobiological processing models in general (Bechara, 2005; Cohen \& Lieberman, 2010), no studies have applied this neurobiological approach to impulsive buying behavior. With the primary objective of addressing this lack of research, the present study brings together behavioral research on impulsive buying with neurobiological research on determinants of impulsiveness. Because visual stimuli are generally assumed to be core drivers of impulsive buying (Verplanken \& Herabadi, 2001), the study examined the explicit effects of merely perceiving product packages.

In order to thoroughly consider the possible effects of exposure to attractive product packaging, it is important to take two central findings into account: First, the perception of attractive marketing stimuli does not lead exclusively to a higher sensitivity of the impulsive, reward-related system, and second, individuals differ significantly in how they respond to attractive stimuli. In Reimann, Zaichowsky, Neuhaus, and Weber (2010), exposure to attractive packages led to increased neural activity in areas associated with the impulsive system and in specific areas associated with the reflective system, such as the ventromedial prefrontal cortex. The observed patterns of neural activity suggest that for at least a significant number of participants, exposure to attractive stimuli is associated not only with increased activity of the impulsive system, but also with increased activity of the reflective system. The results of Van den Bergh, Dewitte, and Warlop (2008, Study 2) also show individual differences in the response to attractive stimuli. In their study, male participants were shown either images of attractive women, or neutral pictures, and were then asked whether they would prefer a lower but immediate reward, or a higher but delayed reward. The comparison of the two exposure conditions revealed that the mere perception of the pictures of attractive women led to an increased desire for immediate rewards and, importantly, the effect of the images of attractive women was stronger for individuals with high sensitivity to rewards across different situations (see also Carver \& White, 1994). Though Van den Bergh et al. (2008) did not examine the effects of product packages, and though they did not measure neural activities, the results are in line with the assumption 
that the effect of attractive stimuli depends on individual differences.

\section{HYPOTHESES}

The present paper tested the assumption that people who differ in their susceptibility toward impulsive buying will also exhibit different neural activation patterns when perceiving attractive product packaging (Reimann et al., 2010; Stoll, Baecke, \& Kenning, 2008). Thus, the main interest was to identify whether the mere perception of an attractive marketing cue leads to a different reaction in people with higher impulsive buying tendencies, as compared to people with lower impulsive buying tendencies. Several studies have shown that impulsive buying behavior is not only affected by context variables, but that interindividual differences in impulsive buying tendencies across different situations may explain a considerable amount of variance (Puri, 1996; Rook \& Fisher, 1995; Verplanken \& Herabadi, 2001; Weun, Jones, \& Beatty, 1998).

To investigate neural responses to the perception of product packaging in participants with variability in impulsive buying tendencies, functional magnetic resonance imaging (fMRI) was applied during the exposure to packages differing in attractiveness (attractive, neutral, and unattractive). Using the Rook-Fisher Scale (Rook \& Fisher, 1995), individual differences in the impulsive buying tendencies were determined by computing an individual buying impulsiveness score. It was presumed that impulsive buying tendencies, to a substantial degree, are linked to heightened sensitivity toward positive and negative (marketing) stimuli (Bechara, 2005; Krieglmeyer, Deutsch, De Houwer, \& De Raedt, 2010), which is the result of a general hyperactivity of the impulsive system and lower activity of the reflective system (Bechara, 2005). This idea is congruent with previous research that has determined a substantial overlap in neural responses to positive and negative stimuli, as compared to neutral stimuli (Breiter et al., 1996; Stark et al., 2005). Therefore, it was hypothesized that with an increase in participants' buying impulsiveness scores, exposure to attractive and unattractive packages (as compared to exposure to neutral packages) will lead to increased neural activations in brain regions associated with an impulsive system, and to decreased neural activations in brain regions associated with a reflective system.

H1: The stronger participants' impulsive buying tendencies, the exposure to attractive or unattractive product packages, compared to neutral packages, will lead to more intensive activity changes in brain areas associated with the impulsive brain system (e.g., ventral striatum [nucleus accumbens], caudate and putamen, amygdala).
H2: The stronger participants' impulsive buying tendencies, the exposure to attractive or unattractive product packages, compared to neutral packages, will lead to less intensive activity changes in regions associated with the reflective brain system (e.g., prefrontal structures [VMPFC, DLPFC]).

With regard to Hypotheses 1 and 2, however, it is important to note that there is not a complete similarity in the neural responses to positive and negative stimuli (Stark et al., 2005). Studies have shown that the impulsive system is involved in the modulation of fast and automatic approach behavior toward positive stimuli, and avoidance behavior away from negative stimuli (e.g., Bechara, 2005; Krieglmeyer et al., 2010). Even if positive stimuli can be easily distinguished from negative stimuli, a hyperactive impulsive system and a weaker reflective system should amplify the responses to these stimuli with a more consistent activation. In particular, the brain regions within the impulsive system that are associated with reward expectation (cf. Knutson, Adams, Fong, \& Hommer, 2001) should show stronger neural activity when participants perceive positive stimuli than when they perceive negative stimuli.

H3: The stronger participants' impulsive buying tendencies, the exposure to attractive product packages, compared to unattractive packages, will lead to stronger activity changes in regions of an impulsive system also associated with reward expectation (striatum).

H4: The stronger the impulsive buying tendencies of participants, the stronger will be the differences between the evaluation of positive and negative product packages.

\section{METHOD AND PROCEDURE}

\section{Participants}

Twenty-two healthy, right-handed individuals (12 women, 10 men, $M_{\text {age }}=27.14$, SD $=4.52$, age range 20 36 years) were recruited for participation in the study. For recruitment, standard criteria for magnetic resonance (MR) examinations were applied-that is, with regard for strong myopia or other relevant constraints of vision, as well as obtaining written informed consent prior to the scanning sessions. An institutional review board $^{2}$ approved the study.

2 The study was approved by an external institution the Freiburg Ethics Commission (FEKI; http://www.feki.com/index.php?id=11 $\& \mathrm{~L}=1)$. 


\section{Stimulus Material}

A pretest was conducted in order to select the stimulus material. In this, 23 female and 28 male participants rated 86 original paper-based packages on a 10point scale ranging from 1 (very unattractive) to 10 (very attractive). The product packages selected were of equal size, screen position, background, and luminance. Based on the judgments of the participants, the packages were classified into three groups. The group of attractive packages $\left(\mathrm{P}^{+}\right)$contained packages with a mean score of 6 or above, the group of neutral packages $\left(\mathrm{P}^{0}\right)$ included packages with a mean score of more than 5 but less than 6 , and the group of unattractive packages $\left(\mathrm{P}^{-}\right)$comprised packages with a mean score of 5 or lower. From the results, the 10 most attractive $\left(\mathrm{P}^{+}\right)$ and the 10 least attractive $\left(\mathrm{P}^{-}\right)$packages, as well as 10 neutral packages $\left(\mathrm{P}^{0}\right)\left(M_{\text {attractive }}=7.08, \mathrm{SD}=0.24\right.$; $\left.M_{\text {neutral }}=5.41, \mathrm{SD}=0.14 ; M_{\text {unattractive }}=3.13, \mathrm{SD}=0.60\right)$ were selected (Stoll, Baecke, \& Kenning, 2008). Attractiveness ratings were entered into an one-way ANOVA (with group: attractive, neutral, unattractive) corrected for repeated measures using the Greenhouse-Geisser (GG) correction criterion, and a significant main effect was found for our classification $\left(\mathrm{P}^{+}, \mathrm{P}^{0}, \mathrm{P}^{-}\right), F(1.23$, $11.1)=279.06, p<0.001, \eta_{\mathrm{p}}{ }^{2}=0.969$.

\section{Experimental Paradigm and Procedure}

Prior to entering the scanner, participants were verbally advised to avoid head movements during the measurement procedure. Inside the fMRI scanner, head fixation was maintained by use of foam pads and a soft headband. Headphones protected against scanner noise and allowed communication. During the main phase of the study, a personal computer in the MR control room was used to present images of the product packages selected from the pretest, and an LCD projector displayed the packaging images on a transparent screen fixed at the rear opening of the MR bore. Participants were instructed to indicate whether they regarded the selected packaging images to be attractive or unattractive.

In detail, the volunteers were initially briefed by projecting the instructions into their visual fields. In a pseudorandomized order, a photo of a product package was presented every 10 seconds. Participants evaluated each of the presented package images four times, for a total of 120 product response judgments. To designate whether a product package was attractive or unattractive, participants pressed one of the two corresponding buttons on a MR-compatible response box. The responses were recorded with the use of specific software (COGENT), and calculated the mean assessment of all three product package categories for each participant. Values ranged from 0 to 1 . High values indicate that participants perceived the product packages in the respective category to be attractive.

After the scanning session, participants were asked to complete a questionnaire, which included the Rook and Fisher's (1995) scale for measuring impulsive buying tendencies. The scale has frequently been applied in previous related research (Kacen \& Lee, 2002; Luo, 2005; Peck \& Childers, 2006; Vohs \& Faber, 2007). Using a 5-point Likert scale ranging from 1 (strongly disagree) to 5 (strongly agree), participants rated the nine items of the scale. The item scores were totaled for each participant in order to calculate an individual buying impulsiveness score with a possible range from 9 to 45 points. Higher values indicate stronger impulsive buying tendencies. The buying impulsiveness scores of the sample varied from a minimum of 11 points to a maximum of 33 points $(M=24.36 ; \mathrm{SD}=5.703 ; \alpha=0.87)$.

In addition, the questionnaire included items used to collect demographic data (e.g., age, gender, net income, work status), and items for assessing self-reported impulsivity and reflection. Participants indicated how accurately 12 attributes described them, using a 7-point scale ranging from 1 (seldom would describe me) to 4 (sometimes describes me) to 7 (usually would describe me). The attributes were taken from a scale designed by Puri (1996) that is often used in research on impulsive behavior (Ramanathan \& Menon, 2006; Wertenbroch, 1998). Five attributes describe impulsivity, and seven attributes describe reflection. Following Puri (1996), the five (impulsivity) and seven (reflection) items were averaged into two subscales. Participant self-description with high values for impulsivity and low values for reflection indicate a judgment of impulsivity.

\section{Image Acquisition}

The study was executed on a 3 Tesla scanner (Magnetom Trio, SIEMENS, Erlangen, Germany). The protocol included a 3D isotropic T1-weighted data set of the whole head, with a measured voxel size of $1.0 \mathrm{~mm}$ edge length for anatomical identification and coregistration into the Talairach space (Talairach \& Tournoux, 1988). Functional images were acquired using a T2*weighted single-shot gradient echo-planar imaging sequence, which covered nearly the entire brain. The data set consisted of 36 transversal slices of $3.6 \mathrm{~mm}$ thickness without a gap, FOV $230 \mathrm{~mm} \times 230 \mathrm{~mm}$, acquired matrix $64 \times 64$, that is, isotropic voxels with $3.6 \mathrm{~mm}$ edge length. Contrast parameters were $\mathrm{TR}=3000 \mathrm{~ms}$, $\mathrm{TE}=50 \mathrm{~ms}$, and flip angle $=90^{\circ}$.

\section{Data Analysis}

Data analysis was conducted with the SPM8-freeware (Friston, 1996; Friston et al., 1994), using MatLab as a working base. The application followed procedures described in Huettel, Song, and McCarthy (2009) and in Poldrack et al. (2007). The data preprocessing consisted of three initial steps. First, to correct for artifacts due to participant head movement in the scanner, all images were realigned by a "rigid body" transformation to the mean image of the session (realignment). 
Second, to compare all participants within the group analysis, all images were normalized and resampled to the standard Montreal Neurological Institute (MNI) template (normalization). Third, to prepare the data for the statistical analysis, all images were smoothed with an $8 \mathrm{~mm}$ full-width-at-half-maximum Gaussian kernel (smoothing; Ashburner, Neelin, Collins, Evans, \& Friston, 1997).

Within the first-level analysis, three onsets were constructed for packaging images regarding their attractiveness level; attractive $\left(\mathrm{P}^{+}\right)$, neutral $\left(\mathrm{P}^{0}\right)$, unattractive $\left(\mathrm{P}^{-}\right)$in order to estimate the general linear model (GLM). The onsets included information designating when and for how long the packaging images were presented during the scan session. We also included realignment parameters as additional covariates. The estimation of the GLM was conducted by fitting a reference hemodynamic response function to each event (onset) in the observed data (Huettel, Song, \& McCarthy, 2009). After the model estimation and in preparation for the second-level (group) analysis, contrasts for each individual participant were defined on the basis of activity differences between $\mathrm{P}^{+}$and $\mathrm{P}^{0}, \mathrm{P}^{+}$ and $\mathrm{P}^{-}$, and $\mathrm{P}^{0}$ and $\mathrm{P}^{-}$.

A one-sample $t$-test was computed within the secondlevel (group) analysis for each contrast $\left(\mathrm{P}^{+}\right.$vs. $\mathrm{P}^{0}, \mathrm{P}^{+}$ vs. $\mathrm{P}^{-}, \mathrm{P}^{0}$ vs. $\mathrm{P}^{-}$), and additionally the buying impulsiveness scores (Rook \& Fisher, 1995) was included as the covariate of interest. The activity changes regarding the covariate were based on individual significant activity within the contrasts extracted from the first-level analysis and the corresponding individual buying impulsiveness score. Main interest was the identification of differences in neural activity between the three attractiveness levels in general, and more specifically of differences in neural activity (positive and negative) related to participants' impulsive buying tendencies. All coordinates were assigned and visualized to cortical regions with the xjView toolbox (Xjview toolbox [version 2011, Computer software]; http://www.alivelearn.net/xjview).

\section{RESULTS}

\section{Preliminary Analysis}

In a preliminary analysis, the correlations between the individual buying impulsiveness scores and demographic variables were examined, and neither a significant correlation of impulsive buying tendencies with age, $r(22)=0.0011, p=0.962$, nor a gender effect with regard to impulsive buying tendencies was found $\left(M_{\text {female }}=24.0, \mathrm{SD}=6.769 ; M_{\text {male }}=24.8, \mathrm{SD}=4.417\right)$, $t(20)=0.321, p=0.752$. Additionally, male and female participants generally did not differ in age $\left(M_{\text {female }}=\right.$ $\left.25.92, \mathrm{SD}=3.288 ; M_{\text {male }}=28.6, \mathrm{SD}=5.502\right), t(20)=$ $1.417, p=0.172$. An analysis of the attractiveness ratings (mean assessment) showed that the perceptions of the packages were congruent with the pretest, and that the categories of attractive, neutral, and unattractive packages derived from the pretest could be used for the analyses of the main study. Attractiveness ratings $\left(M_{\mathrm{P}+}=0.79, \mathrm{SD}=0.18 ; M_{\mathrm{P} 0}=0.56, \mathrm{SD}=0.20 ; M_{\mathrm{P}-}=\right.$ $0.22, \mathrm{SD}=0.13$ ) were entered into an one-way ANOVA (group: attractive, neutral, unattractive) corrected for repeated measures and a significant main effect for our classification was found $\left(\mathrm{P}^{+}, \mathrm{P}^{0}, \mathrm{P}^{-}\right), F(2,42)=72.249$, $p<0.001, \eta_{\mathrm{p}}^{2}=0.775$ (Figure 1 ).

\section{Impulsive Buying Tendencies and Neural Activity During Exposure to Product Packaging}

It was hypothesized that the stronger the participants' impulsive buying tendencies, the exposure to attractive or unattractive product packages, compared to neutral packages, would lead to more intensive activity changes in brain areas associated with the impulsive brain system (Hypothesis 1). Also, it was assumed that the stronger the participants' impulsive buying tendencies, the exposure to attractive or unattractive product packages, compared to neutral packages, would lead to less intensive activity changes in regions associated with the reflective brain system (Hypothesis 2). For exploratory purposes, statistical parametric maps were generated for each contrast and covariation that displayed the $t$-value of each peak voxel meeting a $p<$ 0.005 (uncorrected) significance level with an extent threshold voxel of $k=10$ (cf. Esch et al., 2012; Lieberman \& Cunningham, 2009). Furthermore, small volume correction-a Bonferroni correction (family-wise error $[\mathrm{FWE}]$ ) for multiple tests within a defined region (Poldrack, 2007; Worsley et al., 1996)_for selected areas which we named, a priori, within our hypotheses was applied. Therefore, the corresponding uncorrected $p$-values-and in some cases the small volume corrected $p_{F W E}$-values-are separately stated for activated regions. The results of the fMRI data analysis supported hypotheses one and two-particularly for the comparison between attractive and neutral packages. The complete results are designated in Table 1.

First, correlations between activity changes in regions associated with the impulsive system and impulsive buying tendencies during exposure to attractive packages, as compared to neutral packages were observed. With increasing scores on the buying impulsiveness scale for the contrast between attractive $\left(\mathrm{P}^{+}\right)$and neutral $\left(\mathrm{P}^{0}\right)$ packages, positive differences were found in activity changes within the cingulate gyrus $(p<0.002)$, the thalamus $(p<0.002$; small volume corrected [sphere with $6 \mathrm{~mm}$ ]: $\left.p_{F W E}=0.017\right)$, and the caudate (ventral striatum $)(p<0.003$; small volume corrected [sphere with $6 \mathrm{~mm}$ ]: $p_{F W E}=0.045$ ) (Figure 2), as well as within the parahippocampus $(p<$ 0.003). However, the same pattern of correlations was not observed for the comparison between unattractive and neutral packages. With increasing scores on 


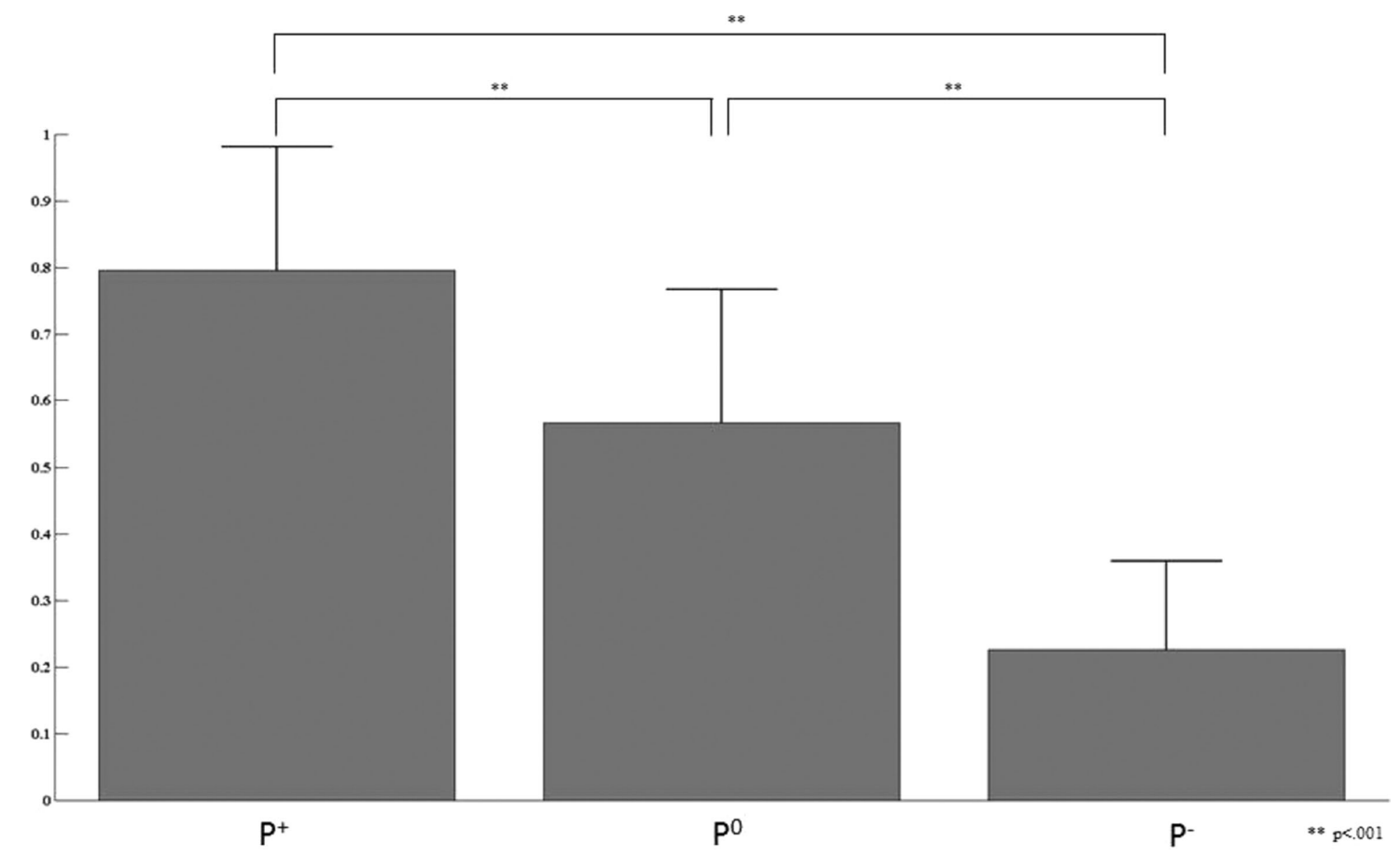

Figure 1. Differences in attractiveness ratings between attractive packages $\left(\mathrm{P}^{+}\right)$, neutral packages $\left(\mathrm{P}^{0}\right)$, and unattractive packages $\left(\mathrm{P}^{-}\right)$.

the buying impulsiveness scale, it was found that the contrast between unattractive $\left(\mathrm{P}^{-}\right)$and neutral packages $\left(\mathrm{P}^{0}\right)$ revealed a positive difference within the cuneus $(p<0.001)$ and precuneus $(p<0.002)$ (Table 1$)$.

Second, negative correlations were observed between activity changes in regions associated with the reflective system and participants' impulsive buying tendencies during exposure to attractive packages. With increasing scores on the buying impulsiveness scale for the contrast between attractive $\left(\mathrm{P}^{+}\right)$and neutral $\left(\mathrm{P}^{0}\right)$ packages, negative differences in activity changes within the cuneus $(p<0.002)$, the DLPFC (BA 9) $(p<0.002$; small volume corrected [sphere with $6 \mathrm{~mm}]: p_{F W E}=0.032$ ) (Figure 3 ), and the middle frontal cortex (BA 8) $(p<0.003)$ were found. Furthermore, during the exposure to unattractive packages a negative correlation between activity in regions associated with the reflective system and impulsive buying tendencies was observed. For the contrast between unattractive $\left(\mathrm{P}^{-}\right)$and neutral packages $\left(\mathrm{P}^{0}\right)$, negative differences were found in activity changes within the ventromedial (BA 10) $(p<0.002$; small volume corrected [sphere with $\left.6 \mathrm{~mm}]: p_{F W E}=0.017\right)$ and dorsolateral (BA 9) $(p<0.001$; small volume corrected [sphere with $6 \mathrm{~mm}$ ]: $p_{F W E}=0.025$ ) (Figure 3) prefrontal cortex, as well as within the superior frontal cortex $(p<0.002)$ (Table 1).

Finally, it was hypothesized that the stronger the impulsive buying tendencies of participants, the exposure to attractive product packages, as compared to unattractive packages, would lead to stronger activity changes in regions of an impulsive system also associated with reward expectation (striatum) (Hypothesis
3). Analysis of the fMRI data confirmed the expected results. With increasing impulsive buying tendencies for the contrast between attractive $\left(\mathrm{P}^{+}\right)$and unattractive product packages $\left(\mathrm{P}^{-}\right)$, positive differences in activity changes were found within the ventral striatum (Figure 2) ( $p<0.001$; small volume corrected [sphere with $\left.6 \mathrm{~mm}]: p_{F W E}=0.012\right)$ and lingual gyrus $(p<0.002)$, as well as negative differences within the cuneus $(p<$ $0.002)$ and the right insula $(p<0.001$; small volume corrected [sphere with $6 \mathrm{~mm}$ ]: $\left.p_{F W E}=0.003\right)($ Figure 4) (Table 1).

\section{Correlations of Impulsive Buying Tendencies with Attractiveness Ratings and Self-Reports of Impulsiveness and Control}

It was presumed that the hyperactivity of the impulsive system amplifies the differences in the perception of attractive and unattractive packages for participants with higher impulsive buying tendencies, as compared to participants with lower impulsive buying tendencies (Hypothesis 4). In line with this assumption, it was found that the difference in attractiveness ratings for packages from the category of attractive packages $\left(\mathrm{P}^{+}\right)$, minus the category of unattractive packages $\left(\mathrm{P}^{-}\right)$, increased with an increase in participants' impulsive buying tendencies, $r(22)=0.429, p=0.046$. Furthermore, positive correlations of impulsive buying tendencies were found with the self-assessment as impulsive, $r(22)=0.455, p=0.033$, and negative correlations with 


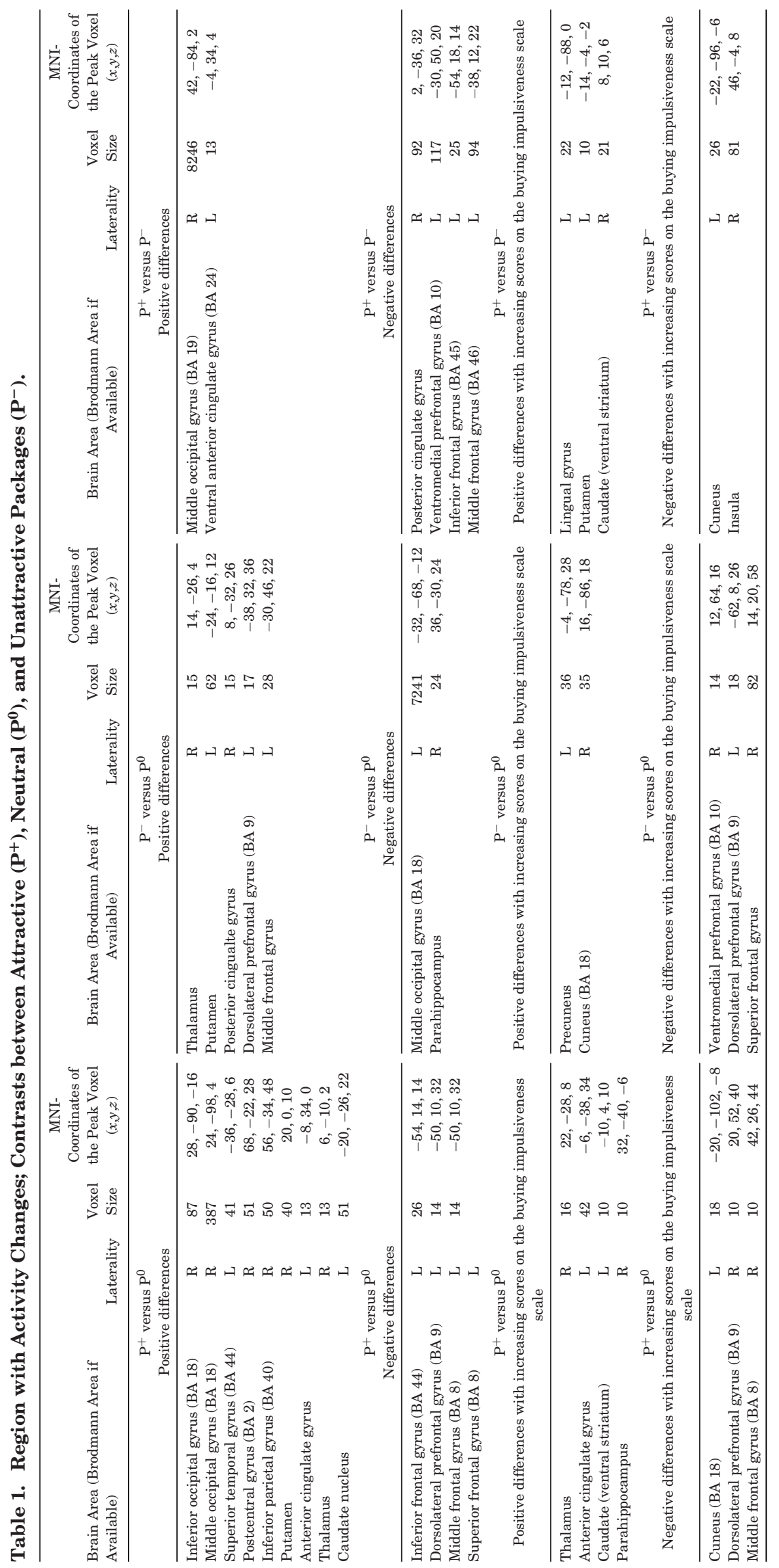



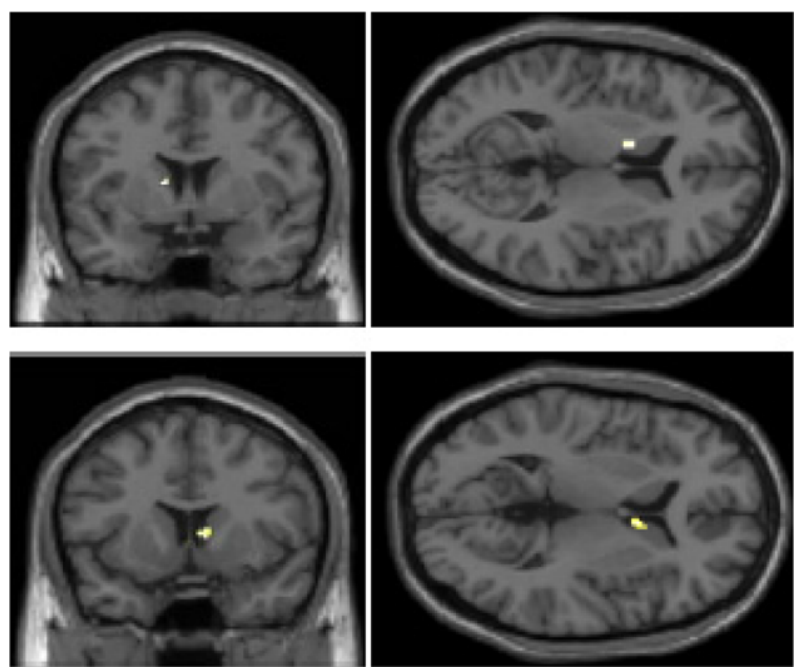

Figure 2. Activity changes within the ventral striatum for attractive versus neutral packages (above) and for attractive versus unattractive packages (below).
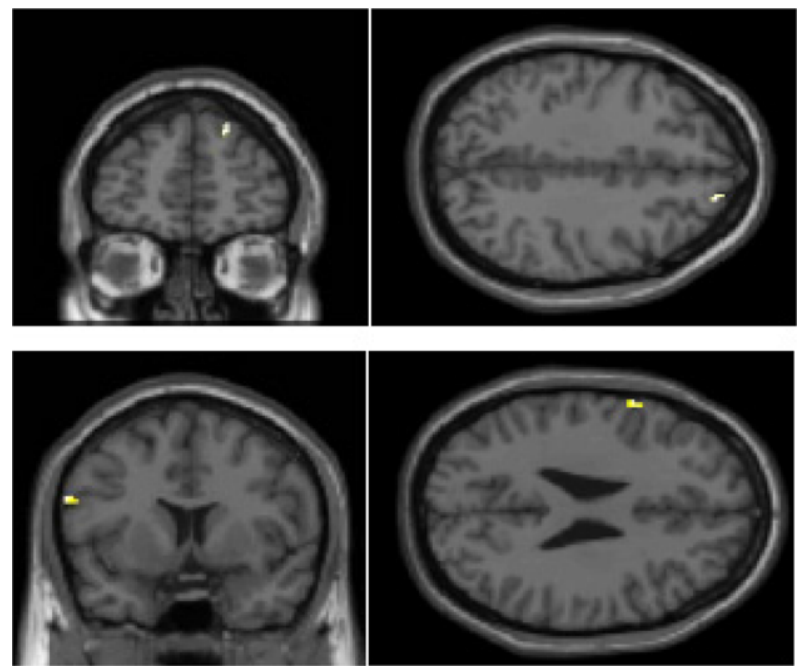

Figure 3. Activity changes within the DLPFC for attractive versus neutral packages (above) and for attractive versus unattractive packages (below).

the self-assessment as reflective, $r(22)=-0.539, p=$ 0.01 .

\section{DISCUSSION}

Aim of the fMRI study was to investigate whether interindividual differences in consumers' impulsive buying tendencies-measured with a scale developed by Rook and Fisher (1995) — affect the perception of product packages that differ in attractiveness (attractive, neutral, and unattractive). The results of the study suggest that there is indeed a corresponding relationship between increasing scores in impulsive buying tendencies of the participants and activity changes in ar-
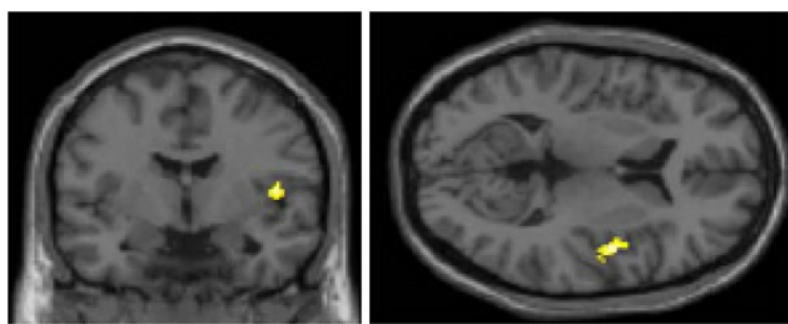

Figure 4. Activity changes within the insula for unattractive versus attractive packages.

eas associated with an impulsive and reflective system (Bechara, 2005; Strack \& Deutsch, 2004).

With regard to areas associated with an impulsive system, more intensive activity changes corresponding to higher impulsive buying tendencies were found within the caudate, the putamen (ventral striatum $/ \mathrm{NaCC}$ ), and the thalamus when comparing attractive versus neutral packaging and attractive versus unattractive packages. It was not possible to identify more intensive activity changes in these areas when comparing unattractive versus neutral packages (Figure 5).

These regions-especially the putamen and caudate-are key structures of the impulsive system and what is referred to as a "reward system" of the brain (Breiter, Aharon, Kahneman, Dale, \& Shizgal, 2001; Dalgleish, 2004; Deppe, Schwindt, Kugel, Plassmann, \& Kenning, 2005a, 2005b, 2007; Knutson, Westdorp, Kaiser, \& Hommer, 2000; Komura et al., 2001; Lamm, Nussbaum, Meltzoff, \& Decety, 2007; O'Doherty, 2004). Moreover, the caudate nucleus is often associated with emotions, motivated behavior (Delgado, Locke, Stenger, \& Fiez, 2003; Haruno, \& Kawato, 2006), and customer loyalty (Plassmann, Kenning, \& Ahlert, 2007), and seems to be involved in obsessive compulsive disorders (Riffkin et al., 2005). The ventral area of the caudate and the putamen form the ventral striatum, where the nucleus accumbens is located. The nucleus accumbens plays a central role in the dopamine and reward system of the brain (Castro, Merchut, Neafsey, \& Wurster, 2002) and has repeatedly been shown to be involved in the perception of favorable products (Knutson, Rick, Wimmer, Prelec, \& Loewenstein, 2007), or in the anticipation of monetary rewards (Knutson et al., 2001). Activity changes in the ventral striatum even seem to be a strong predictor of purchase behavior (Grosenick, Greer, \& Knutson, 2008; Knutson et al., 2007). Also, the thalamus is associated with reward processing and the prediction of future reward values (Knutson et al., 2000; Komura et al., 2001).

Taking into account these neurobiological findings, with regard to areas associated with an impulsive system, the prediction (Hypothesis 1) that the exposure to attractive or unattractive product packages, compared to neutral packages, will lead to more intensive activity changes in brain areas associated with the impulsive 


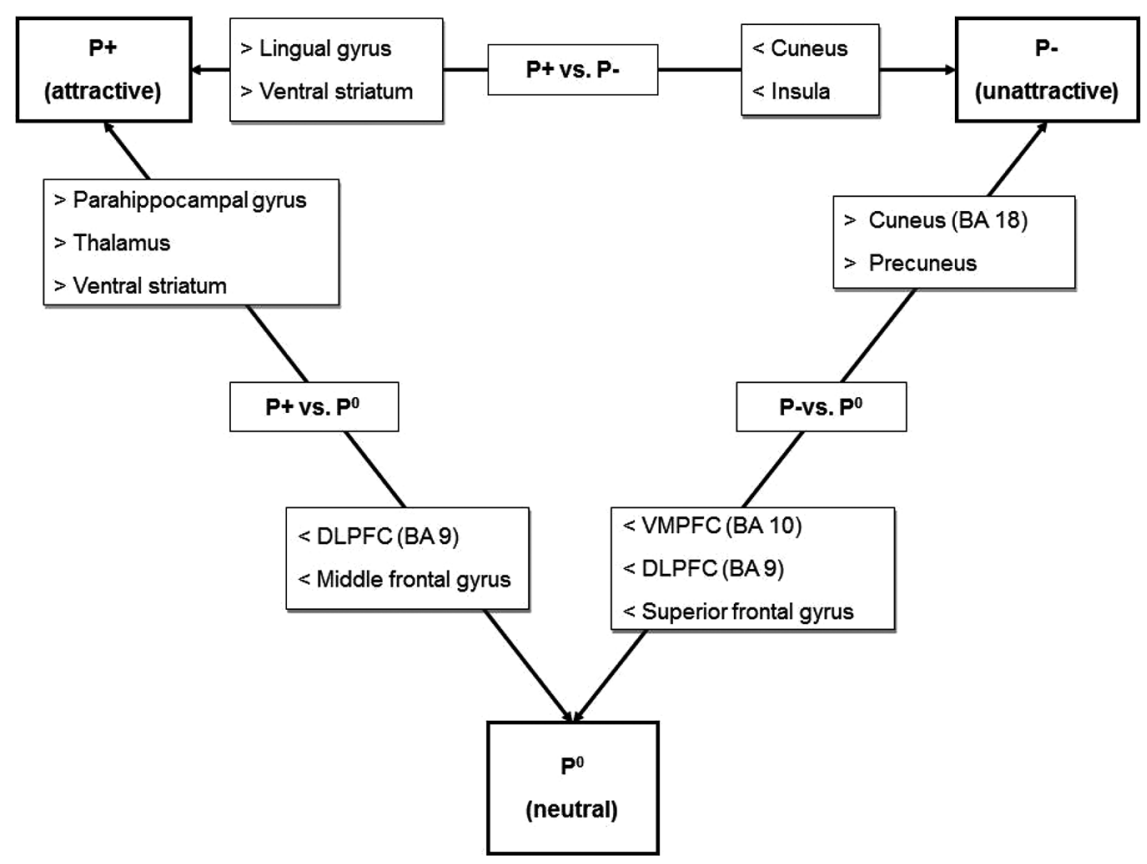

Figure 5. Activity changes for all contrasts corresponding to higher impulsive buying tendencies.

brain system (i.e., putamen and caudate) was confirmed only for attractive packages, and not for unattractive packages. A possible explanation for this missing effect of unattractive stimuli on brain regions associated with an impulsive system is simply that unattractive packages are much less intense in negativity than are the negative stimuli used in previous studies (Stark et al., 2005), such as images that provoke a response of disgust. These results (i.e., ventral striatum $/ \mathrm{NaCC}$ ) also confirm Hypothesis 3, which presumes that the higher the impulsive buying tendencies of participants, the exposure to attractive product packages, compared to unattractive packages, would lead to stronger activity changes in regions of an impulsive system also associated with reward expectation. People with higher impulsive buying tendencies may see attractive packages as even more rewarding (Reimann et al., 2010; Stoll, Baecke, \& Kenning, 2008) than would people with lower impulsive buying tendencies. Also, it was discovered that for participants with higher buying impulsiveness tendencies scores, the perception of unattractive versus attractive packages led to more intensive activity in the insula cortex. Activity changes in the insula cortex, which is linked to the representation of patterns of affective states from prior experiences of reward and punishment (Bechara, 2005), have been associated with uncertainty, pain, and negative emotions (including anger, disgust, and fear) (Eisenberger \& Lieberman, 2004; Knutson et al., 2007; Sanfey, Rilling, Aronson, Nystrom, \& Cohen, 2003). Studies have also shown the changes to be greater for unattractive stimuli than for attractive stimuli (Krendl, Macrae, Kelley, Fugelsang, \& Heatherton, 2006; O’Doherty et al., 2003; Tsukiura \& Cabeza, 2011).
Furthermore, the neurobiological findings are supported by Hypothesis 4, where a more consistent evaluation of attractive and unattractive packages was presumed. In accordance with Hypothesis 4, a positive correlation was found between higher buying impulsiveness tendencies and increasing differences in the evaluation of attractive product packages minus the evaluation of unattractive packages. This behavioral result, in line with the findings from the brain imaging study, corresponds to previous research showing that the impulsive system is involved in the modulation of fast and automatic approach behavior toward positive stimuli, and avoidance behavior away from negative stimuli (Bechara, 2005; Krieglmeyer et al., 2010).

Additionally, with regard to areas associated with a reflective system, when comparing attractive versus neutral packages and unattractive versus neutral packages, less intensive activity changes corresponding to higher impulsive buying tendencies were found within the VMPFC and DLPFC (Figure 5). The VMPFC and the DLPFC are generally associated with willpower, rational thought processes, and inhibition (Bechara, 2005; Brass \& Haggart, 2007; McClure, York, \& Montague, 2004; McGuire \& Botvinick, 2010; Sanfey et al., 2003). In particular, the DLPFC is believed to play a prominent role in cognitive control, working memory, and self-control (Hare, Camerer, \& Rangel, 2009; Knoch, Pascual-Leone, Meyer, Treyer, \& Fehr, 2006; McClure, York, \& Montague, 2004; Plassmann, O’ Doherty, \& Rangel, 2008; Sanfey et al., 2003; Schaefer, Berens, Heinze, \& Rotte, 2006). Also, the VMPFC is a crucial structure of the reflective system and is associated with the evocation of emotions from previous experiences through recall or imagination (Bechara \& 
Damasio, 2005). Impairments in this area correspond to compromised decision making, impulsivity, and a diminished capacity for responding to punishments, and they lead to a loss of self-directed behavior in favor of more automatic, sensory-driven behavior (Bechara, 2005; Bechara \& Damasio, 2005; Bechara, Damasio, Tranel, \& Damasio, 1997; Shiv et al., 2005).

Therefore, taking into account these neurobiological findings with regard to areas associated with a reflective system, the prediction (Hypothesis 2) that the exposure to attractive or unattractive product packages, compared to neutral packages, will lead to less intensive activity changes in brain areas associated with the reflective impulsive brain system (i.e., VMPFC, DLPFC) is confirmed for both attractive and unattractive stimuli. As well, the prediction is in accordance with dualsystem approach theories (Bechara, 2005; Gray, 1982; Strack \& Deutsch, 2004) that stress impulsive behavior as the result of not only a hyperactive impulsive system, but also of a weaker reflective system. It can be assumed that in persons with stronger buying impulsiveness tendencies, the impulsive brain system prevails in buying contexts because the reflective system is not able to control impulses emerging from the impulsive system.

\section{Limitations and Further Research}

Overall, the results serve to complete previous research on the responses to positive and negative stimuli (Stark et al., 2005), and show that the perception of product packages is indeed moderated by individual differences in impulsive buying tendencies, even on a neurophysiological level. Accordingly, the results support the use of an impulsive and reflective system to explain impulsive behavior (Bechara, 2005; Strack \& Deutsch, 2004).

With regard to limitations of the study and implications for future research, it is important to consider the ongoing debate on whether or not individual tendencies toward impulsive buying can be conceptualized as a consumer trait. Some researchers argue thatsimilar to impulsivity in general-buying impulsiveness is rooted in the personality of the consumers. According to this view, the buying impulsiveness trait is responsible for a specific way of thinking and a specific behavioral pattern in buying situations (Rook \& Fisher, 1995). The trait is also related to other personalitybased differences such as extraversion (Verplanken \& Herabadi, 2001), individual differences in basic cognitive processes (Büttner et al., 2013; Genschow et al., 2013), or individual differences in shopping orientation (Büttner, Florack, \& Göritz, in press, 2013). However, there is also evidence that (buying) impulsiveness cannot be considered to be a personality trait, generally (Kerwin, Woodside, \& Hantula, 2012). In some cases the measurement of impulsiveness as a trait does not correlate with actual corresponding behaviorthat is, delayed discounting (Smith \& Hantula, 2009)or depends on the actual purchase behavior (Kerwin,
Woodside, \& Hantula, 2012) or other situational influences (Shiv \& Fedorikhin, 1999). Future research, behavioral and neuroscientific, should address this discussion by investigating different situational influences and product types (i.e., hedonic or functional products), as well as the correspondence of different measurements of impulsiveness or impulsive buying behavior and actual behavior. Nevertheless, the study confirms the complementary insights for impulsivity research obtained through the application of neuroimaging to the investigation of consumer behavior-and in this case the specific phenomenon of impulsive buying.

\section{REFERENCES}

Ambler, T., Braeutigam, S., Stins, J., Rose, S., \& Swithenby, S. (2004). Salience and choice: Neural correlates of shopping decisions. Psychology \& Marketing, 21, 247-261.

Ashburner, J., Neelin, P., Collins, L. D., Evans, A., \& Friston, K. J. (1997). Incorporating prior knowledge into image registration. Neuroimage, 6, 344-352.

Beatty, S., \& Ferrell, M. E. (1998). Impulse buying: Modeling its precursors. Journal of Retailing, 74, 169-191.

Bechara, A. (2005). Decision making, impulse control and loss of willpower to resist drugs: A neurocognitive perspective. Nature Neuroscience, 8, 1458-1463.

Bechara, A., \& Damasio, A. R. (2005). The somatic marker hypothesis: A neural theory of economic decision. Games and Economic Behavior, 52, 336-372.

Bechara, A., Damasio, H., Tranel, D., \& Damasio, A. R. (1997). Deciding advantageously before knowing the advantageous strategy. Science, 275, 1293-1295.

Bloch, P. H. (1995). Seeking the ideal form: Product design and consumer response. Journal of Marketing, 59, 16-29.

Brass, M., \& Haggart, P. (2007). To do or not to do: The neural signature of self-control. Journal of Neuroscience, 27, 91419145.

Breiter, H. C., Etcoff, N. L., Whalen, P. J., Kennedy, W. A., Rauch, S. L., Buckner, R. L., et al. (1996). Response and habituation of the human amygdala during visual processing of facial expression. Neuron, 17, 875-887.

Breiter, H. C., Aharon, I., Kahneman, D., Dale, A., \& Shizgal, P. (2001). Functional imaging of neural responses to expectancy and experience of monetary gains and losses. Neuron, 30, 619-639.

Burns, K., \& Bechara, A. (2007). Decision making and free will: A neuroscience perspective. Behavioral Sciences and the Law, 25, 263-280.

Büttner, O., Florack, A., \& Göritz, A. (in press). Shopping orientation as a stable consumer disposition and its influence on consumers' evaluations of retailer communication. European Journal of Marketing.

Büttner, O., Florack, A., \& Göritz, A. (2013). Shopping orientation and mindsets: How motivation influences consumer information processing during shopping. Psychology and Marketing, 30, 779-793.

Büttner, O., Florack, A., Leder, H., Paul, M., Serfas, B., \& Schulz, A.-M. (2013). Hard to ignore: Impulsive buyers show an attentional bias in shopping situations. Social Psychological and Personality Science.

Carver, C. S., \& White, T. L. (1994). Behavioral inhibition, behavioral activation, and affective responses to impending 
reward and punishment: The BIS/BAS scales. Journal of Personality and Social Psychology, 67, 319-333.

Castro, A. J., Merchut, M. P., Neafsey E. J., \& Wurster R. D. (2002). Neuroscience: An outline approach. St. Louis, MI: Mosby Inc.

Cohen, J. R., \& Lieberman, M. D. (2010). The common neural basis of exerting self-control in multiple domains. In Y. Trope, R. Hassin, \& K. N. Ochsner (Eds.), Self control in society, mind, and brain (pp. 141-160). Oxford, UK: Oxford University Press.

Dalgleish, T. (2004). The emotional brain. Nature Reviews Neuroscience, 5, 582-589.

Dawe, S., Gullo, M. J., \& Loxton, N. J. (2004). Reward drive and rash impulsiveness as dimensions of impulsivity: Implications for substance misuse. Addictive Behaviors, 29, 1389-1405.

Delgado, M. R., Locke, H. M, Stenger, V. A., \& Fiez, J. A. (2003). Dorsal striatum responses to reward and punishment: Effects of valence and magnitude manipulations. Cognitive, Affective, and Behavioral Neuroscience, 3, 2738.

Deppe, M., Schwindt, W., Kugel, H., Plassmann, H., \& Kenning, P. (2005a). Nonlinear responses within the medial prefrontal cortex reveal when specific implicit information influences economic decision-making. Journal of Neuroimaging, 15, 171-182.

Deppe, M., Schwindt, W., Krämer, J., Kugel, H., Plassmann, H., Kenning, P., et al. (2005b). Evidence for a neural correlate of a framing effect: Bias-specific activity in the ventromedial prefrontal cortex during credibility judgments. Brain Research Bulletin, 67, 413-421.

Deppe, M., Schwindt, W., Pieper, A., Kugel, H., Plassmann, H., Kenning, P., et al. (2007). Anterior cingulate reflects susceptibility to framing during attractiveness evaluation. NeuroReport, 18, 1119-1123.

Dittmar, H., \& Drury, J. (2000). Self-image-Is it in the bag? A qualitative comparison between 'ordinary' and 'excessive' consumers. Journal of Economic Psychology, 21, 109-142.

Eisenberger, N. I., \& Lieberman, M. D. (2004). Why rejection hurts: A common neural alarm system for physical and social pain. Trends in Cognitive Neuroscience, 8, 294-300.

Esch, F.-R., Möll, T., Schmitt, B., Elger, C. E., Neuhaus, C., \& Weber, B. (2012). Brands on the brain: Do consumers use declarative information or experienced emotions to evaluate brands?. Journal of Consumer Psychology, 22, 75-85.

Friese, M., Wänke, M., \& Plessner, H. (2006). Implicit consumer preferences and their influence on product choice. Psychology \& Marketing, 23, 727-740.

Friston, K. J. (1996). Statistical parametric mapping and other analyses of functional imaging data. In A. W. Toga \& J. C. Mazziotta (Eds.), Brain mapping: The methods (pp. 363-386). New York, NY: Academic Press.

Friston, K. J., Holmes, A. P., Worsley, K. J., Poline, J. B., Frith, C. D., \& Frackowiak, R. S. J. (1994). Statistical parametric maps in functional imaging: A general linear approach. Human Brain Mapping, 2, 189-210.

Genschow, O., Florack, A., Chib, V., Shimojo, S., Scarabis, M., \& Wänke, M. (2013). Reaching for the (product)stars: Measuring recognition and approach speed to get insights into consumer choice. Basic and Applied Social Psychology, $35,298-315$.

Gray, J. A. (1982). Précis of the neuropsychology of anxiety: An inquiry into the functions of the septo-hippocampal system. Behavioral Sciences, 5, 469-534.

Grosenick, L., Greer, S., \& Knutson, B. (2008). Interpretable classifiers for fMRI improve prediction of purchases. IEEE
Transactions on Neural Systems and Rehabilitation Engineering, 16, 539-548.

Gutierrez, B. P. B. (2004). Determinants of planned and impulse buying: The case of the Philippines. Asia Pacific Management Review, 9, 1067-1078.

Hare, T., Camerer, C., \& Rangel, A. (2009). Self-control in decision-making involves modulation of the vmPFC valuation system. Science, 324, 646-648.

Haruno, M., \& Kawato, M. (2006). Different neural correlates of reward expectation and reward expectation error in the putamen and caudate nucleus during stimulus-actionreward association learning. Journal of Neurophysiology, 95, 948-959.

Hausman, A. (2000). A multi-method investigation of consumer motivations in impulse buying behavior. Journal of Consumer Marketing, 17, 403-426.

Huettel, S. A., Song, A. W., \& McCarthy, G. (2009). Functional magnetic resonance imaging. Sunderland, MA: Sinauer Associates.

Jentsch, J. D., \& Taylor, J. R. (1999). Impulsivity resulting from frontostriatal dysfunction in drug abuse: Implications for the control of behavior by reward-related stimuli. Psychopharmacology, 146, 373-390.

Kacen, J. J., \& Lee, J. L. (2002). The influence of culture on consumer impulsive buying behavior. Journal of Consumer Psychology, 12, 163-176.

Kaufman-Scarborough, C., \& Cohen, J. (2004). Unfolding consumer impulsivity: An existential-phenomenological study of consumers with attention deficit disorder. Psychology \& Marketing, 21, 637-669.

Kerwin, M. L., Woodside, M., \& Hantula, D. A. (2012). Consumer choices among women in drug treatment: A behavioral economic analysis. Journal of Applied Social Psychology, 42, 834-849.

Knoch, D., Pascual-Leone, A., Meyer, K., Treyer, V., \& Fehr, E. (2006). Diminishing reciprocal fairness by disrupting the right prefrontal cortex. Science, 314, 829-832.

Knutson, B., Westdorp, A., Kaiser, E., \& Hommer, D. (2000). fMRI visualization of brain activity during a monetary incentive delay task. NeuroImage, 12, 20-27.

Knutson, B., Adams, C. M., Fong, G. W., \& Hommer, D. (2001). Anticipation of increasing monetary reward selectively recruits nucleus accumbens. Journal of Neuroscience, 21, $1-5$.

Knutson, B., Rick, S., Wimmer, G. E., Prelec, D., \& Loewenstein, G. (2007). Neural predictors of purchase. Neuron, 53, 147-156.

Kollat, D. T., \& Willett, R. P. (1967). Customer impulse purchasing behavior. Journal of Marketing Research, 4, 21-31.

Komura, Y., Tamura, R., Uwano, T., Nishijo, H., Kaga, K., \& Ono, T. (2001). Retrospective and prospective coding for predicted reward in the sensory thalamus. Nature, 412, 546-549.

Kotler, P., \& Rath, G. A. (1984). Design-A powerful but neglected strategic tool. Journal of Business Strategy, 5, 1621.

Krendl, A. C., Macrae, C. N., Kelley, W. M., Fugelsang, J. A., $\&$ Heatherton, T. F. (2006). The good, the bad, and the ugly: An fMRI investigation of the functional anatomic correlates of stigma. Social Neuroscience, 1, 5-15.

Krieglmeyer, R., Deutsch, R., De Houwer, J., \& De Raedt, R. (2010). Valence activates approach-avoidance behavior independently of evaluation and approach-avoidance intentions. Psychological Science, 21, 607-613.

Lamm, C., Nussbaum, H. C., Meltzoff, A. N., \& Decety, J. (2007). What are you feeling? Using functional magnetic 
resonance imaging to assess the modulation of sensory and affective responses during empathy for pain. PLoS One, 2, $1-16$.

Lieberman, M. D. (2007). Social cognitive neuroscience: A review of core processes. Annual Review of Psychology, 58, 259-289.

Lieberman, M. D., \& Cunningham, W. A. (2009). Type I and type II error concerns in fMRI research: Re-balancing the scale. Social Cognitive and Affective Neuroscience, 4, $423-238$.

Luo, X. (2005). How does shopping with others influence impulsive purchasing? Journal of Consumer Psychology, 15, 288-294.

McClure, S. M., York, M. K., \& Montague, P. R. (2004). The neural substrates of reward processing in humans: The modern role of fMRI. Neuroscientist, 10, 260-268.

McGuire, J. T., \& Botvinick, M. M. (2010). Prefrontal cortex, cognitive control, and the registration of decision costs. Proceedings of the National Academy of Sciences of the United States of America, 107, 7922-7926.

O'Doherty, J. P. (2004). Reward representations and rewardrelated learning in the human brain: Insights from neuroimaging. Current Opinion in Neurobiology, 14, 769-776.

O’Doherty, J., Winston, J., Critchley, H., Perrett, D., Burt, D. M., \& Dolan, R. J. (2003). Beauty in a smile: The role of medial orbitofrontal cortex in facial attractiveness. Neuropsychologia, 41, 147-155.

Peck, J., \& Childers, T. L. (2006). If I touch it I have to have it: Effects of need for touch on impulse purchasing. Journal of Business Research, 59, 765-769.

Pickering, A. D., \& Gray, J. A. (1999). The neuroscience of personality. In L. A. Pervin \& O. P. John (Eds.), Handbook of personality (pp. 277-299). New York, NY: Guilford Press.

Plassmann, H., Kenning, P., \& Ahlert, D. (2007). Why companies should make their customers happy: The neural correlates of customer loyalty. Advances in Consumer Research, 34, 735-739.

Plassmann, H., O'Doherty, J., \& Rangel, A. (2008). Neural encoding of WTP computation during simple purchasing decisions. Advances in Consumer Research, 35, 129.

Poldrack, R. A. (2007). Region of interest analysis for fMRI. Social Cognitive and Affective Neuroscience, 2, 67-70.

Poldrack, R. A., Fletcher, P. C., Henson, R. N., Worsley, K. J., Brett, M., \& Nichols, T. E. (2007). Guidelines for reporting an fMRI study. NeuroImage, 40, 409-414.

Puri, R. (1996). Measuring and modifying consumer impulsiveness: A cost-benefit accessibility framework. Journal of Consumer Psychology, 5, 87-113.

Ramanathan, S., \& Menon, G. (2006). Time-varying effects of chronic hedonic goals on impulsive behavior. Journal of Marketing Research, 43, 628-641.

Reimann, M., Zaichowsky, J., Neuhaus, C., Bender, T., \& Weber, B. (2010). Aesthetic package design: A behavioral, neural, and psychological investigation. Journal of Consumer Psychology, 20, 431-441.

Riffkin, J., Yücel, M., Maruff, P., Wood, S. J., Soulsby, B., Olver, J., et al. (2005). A manual and automated MRI study of anterior cingulated and orbito-frontal cortices, and caudate nucleus in obsessive-compulsive disorder: Comparison with healthy controls and patients with schizophrenia. Psychiatry Research, 128, 99-113.

Rook, D. (1987). The buying impulse. Journal of Consumer Research, 14, 189-199.
Rook, D., \& Fisher, R. J. (1995). Normative influences on impulsive buying behavior. Journal of Consumer Research, 22, 305-313.

Sanfey, A. G., Rilling, J. K., Aronson, J. A., Nystrom, L. E., \& Cohen, J. D. (2003). The neural basis of economic decision-making in the ultimatum game. Science, 300, 1755-1758.

Schaefer, M., Berens, H., Heinze, H. J., \& Rotte, M. (2006). Neural correlates of culturally familiar brands of car manufacturers. NeuroImage, 31, 861-865.

Shiv, B., Bechara, A., Levin, I., Alba, J. W., Bettman, J. R., Dube, L., et al. (2005). Decision neuroscience. Marketing Letters, 16, 375-386.

Shiv, B., \& Fedorikhin, A. (1999). Heart and mind in conflict: The interplay of affect and cognition in consumer decision making. Journal of Consumer Research, 26, 278-292.

Shiv, B., \& Fedorikhin, A. (2002). Spontaneous versus controlled influences of stimulus-based affect on choice behavior. Organizational Behavior and Human Decision Processes, 87, 342-370.

Smith, C. L., \& Hantula, D. A. (2009). Methodological considerations in the study of delay-discounting in intertemporal choice: A comparison of tasks and modes. Behavior Research Methods, 40, 940-953.

Spears, N. (2006). Just moseying around and happening upon it versus a master plan: Minimizing regret in impulse versus planned sales promotion purchases. Psychology \& Marketing, 23, 57-73.

Stark, R., Schienle, A., Girod, C., Walter, B., Kirsch, P., \& Blecker, C. (2005). Erotic and disgust-inducing picturesDifferences in the hemodynamic responses of the brain. Biological Psychology, 70, 19-29.

Stoll, M., Baecke, S., \& Kenning, P. (2008). What they see is what they get? An fMRI-study on neural correlates of attractive packaging. Journal of Consumer Behaviour, 7, 342-359.

Strack, F., \& Deutsch, R. (2004). Reflective and impulsive determinants of social behavior. Personality and Social Psychology Review, 8, 220-247.

Strack, F., Werth, L., \& Deutsch, R. (2006). Reflective and impulsive determinants of consumer behavior. Journal of Consumer Psychology, 16, 205-216.

Talairach, J., \& Tournoux, P. (1988). Co-planar stereotaxic atlas of the human brain: 3-D proportional system: An approach to cerebral imaging. New York: Thieme Medical Publishers.

Tsukiura, T., \& Cabeza, R. (2011). Shared brain activity for aesthetic and moral judgments: Implications for the beauty-is-good stereotype. Social Cognitive and Affective Neuroscience, 6, 138-148.

Van den Bergh, B., Dewitte, S., \& Warlop, L. (2008). Bikinis instigate generalized impatience in intertemporal choice. Journal of Consumer Research, 35, 85-97.

Verplanken, B., \& Herabadi, A. (2001). Individual differences in impulsive buying tendency: Feeling and no thinking. European Journal of Personality, 15, 71-83.

Vohs, K. D., \& Faber, R. J. (2007). Spent resources: Selfregulatory resource availability affects impulse buying. Journal of Consumer Research, 33, 537-547.

Weinberg, P., \& Gottwald, W. (1982). Impulsive buying as a result of emotions. Journal of Business Research, 10, 43-57.

Wertenbroch, K. (1998). Consumption self-control by rationing purchase quantities of virtue and vice. Marketing Science, 17, 317-337. 
Weun, S., Jones, M. A., \& Beatty, S. E. (1998). The development and validation of the impulse buying tendency scale. Psychological Reports, 82, 1123-1133.

Wood, M. (1998). Socio-economic status, delay of gratification, and impulse buying. Journal of Economic Psychology, 19, 295-320.

Worsley, K. J., Marrett, S., Neelin, P., Vandal, A. C., Friston K. J., \& Evans, A. C. (1996). A unified statistical approach for determining significant signals in images of cerebral activation. Human Brain Mapping, 4, 58-73.

Correspondence regarding this article should be sent to: Ass. Prof. Dr. Marco Hubert, Department of Corporate Management and Economics, Zeppelin University, Am Seemooser Horn 20, 88045 Friedrichshafen, Germany (marco.hubert@zu.de). 